\section{Cyn d 1 airborne allergen in a Southern Brazilian city}

\section{Cinthya Covessi Thom de Souza ${ }^{1 *}$, Nelson Augusto Rosario Filho', Ernesto Akio Taketomi ${ }^{2}$, Juliana Silva Miranda² and Ricardo Henrique Moreton Godoi ${ }^{3}$}

\author{
${ }^{1}$ Department of Pediatrics, Federal University of Paraná, Brazil \\ ${ }^{2}$ Laboratory of Allergy and Clinical Immunology, Biomedical Science Institute, Federal University of \\ Uberlândia, Brazil \\ ${ }^{3}$ Department of Environmental Engineering, Federal University of Paraná, Brazil
}

By researching the factors related to exposure to indoor and outdoor allergens, such seasons, climate changes and particulate matter, allergists can screen the sensitization profile of individuals according to their exposures and conduct preventive treatment and individualized immunotherapy. Molecular allergology has improved aerobiological screening of allergenic components toward more specific results on allergic exposure, sensitization, and symptoms [1,2]. The Enzyme-Linked Immunosorbent Assay (ELISA) is a colorimetric enzyme immunoassay technique used to quantify soluble substances such as proteins, peptides, antibodies, and hormones. Due to its high sensitivity and specificity, ELISA can quantify substances at low concentrations, such as allergens [3].

In Brazil, pollinosis, also known as hay fever or seasonal allergic rhinitis, is mainly attributed to Poaceae grasses [4]. In the 1970s, the first case reports of the disease appeared in the southern region of Brazil, in individuals with sensitization to pollen extracts and spring symptoms of allergic rhinitis and conjunctivitis [5]. A local air pollen count revealed grass pollen between September and December, the spring season, with a peak on the second half of November [6]. In the temperate climate of southern Brazil, Lolium multiflorum (rye grass) was found to be the main allergenic sensitizing grass. The climate in southern Brazil consists of lower temperatures during winter that precede an exuberant pollen season in spring. Subtropical grass species like Cynodon dactylon (Bermuda grass) and Paspalum notatum (Bahia grass) became increasingly prominent due to their invasiveness and ubiquity [7]. In addition, climate change, global warming, and air pollution are gradually contributing to an intense growth and distribution of allergenic plants, prolonged pollination periods, and an increased pollen allergenicity $[8,9]$.

Group-1 grass pollen allergens are present in all
More Information

*Address for Correspondence: Cinthya Covessi Thom de Souza, Department of Pediatrics, Federal University of Paraná, 181 General Carneiro Street-14o Floor, Curitiba, CEP 80060-240, Paraná, Brazil, Tel: +55 4133607842 ; Email: cinthyathom@yahoo.com.br

Submitted: February 11, 2021 Approved: February 25, 2021 Published: February 26, 2021

How to cite this article: de Souza CCT, Filho NAR, Taketomi EA, Miranda JS, Godoi RHM. Cyn d 1 airborne allergen in a Southern Brazilian city. Arch Asthma Allergy Immunol. 2021; 5: 014-016.

\section{DOI: 10.29328/journal.aaai.1001024}

Copyright: @ 2021 de Souza CCT, et al. This is an open access article distributed under the Creative Commons Attribution License, which permits unrestricted use, distribution, and reproduction in any medium, provided the original work is properly cited.

Keywords: Pollinosis; Grass pollen; Cynodon; Air samples; ELISA

Check for updates

OPEN ACCESS

species of Poaceae. However, Group-1 allergens have limited cross-reactivity between subfamilies of temperate and subtropical climate grasses. Cyn $\mathrm{d} 1$ is a major allergen of C. dactylon, followed by Cyn $\mathrm{d} 4$. Phl p 1 and Phl p 5 are the major Pooideae pollen allergens. In light of the high allergenic homology between Phleum pratense and L. multiflorum, the allergenic components of the former may be interpreted to sensitization to the latter $[10,11]$. Through a series of Immunoglobulin E (IgE) microarray analyses, Araujo, et al. [12] demonstrated sensitization to several of allergens in children with asthma and allergic rhinitis in Curitiba, southern Brazil; $16.8 \%$ of those children were sensitized to Cyn $\mathrm{d} 1$, while $14.8 \%$ were sensitized to $\mathrm{Phl} \mathrm{p} 1$ and $12.9 \%$ to $\mathrm{Phl} \mathrm{p} 4$. Six out of 17 children were only sensitized to Cyn $\mathrm{d} 1$ and $\mathrm{Phl}$ p 4, suggesting true sensitization to $C$. dactylon.

This study was prompted by the broad distribution of Bermuda grass in subtropical and tropical areas, and the growing sensitization rates to Cynodon dactylon in some areas of Brazil. The present study, the first of its kind in Brazil, was undertaken to determine airborne Cyn d 1 in Maringá, a large city in southern Brazil. To this end, we obtained air samples using a total particulate impactor placed outdoors, $90 \mathrm{~cm}$ from the ground, with a flow rate of $1,13 \mathrm{~m}^{3}$ of air/hour. The collection point was an urban area, at latitude $23.41 \mathrm{~S}$, 
longitude $51.97 \mathrm{~W}, 537 \mathrm{~m}$ above sea level. The samples were collected from March 2017 to March 2018. Seventy filters were collected during the 12 months with a median interval of 5 days (ranging from 1 to 14 days). To elute the filters, small pieces $\left(3 \mathrm{~cm}^{2}\right)$ were incubated with $\mathrm{f} \mathrm{NH4HCO3,0.1 \%} \mathrm{BSA}$ (bovine serum albumin) and $0.1 \%$ Tween $20^{\circledR}$ (polysorbate 20) in an orbital shaker overnight at $4{ }^{\circ} \mathrm{C}$. The solution was then centrifuged twice at $4000 \mathrm{rpm}$ for 5 minutes and the supernatants extracted and stored at $-80{ }^{\circ} \mathrm{C}$. Finally, the samples were analyzed for Cyn d 1 (ALK-Abelló ${ }^{\circledR}$ ) via ELISA, a method with highly specificity and a detection limit of $0.24 \mathrm{ng} / \mathrm{mL}$ [13]. The test was performed with samples, controls and blank filter, all in duplicate.

We also collected daily meteorological data from the city of Maringá during the study at the weather station (OMM:83767, latitude 23,4 S; longitude 51,91 W; $542 \mathrm{~m}$ above the sea). Temperature, relative humidity, rain precipitation, insolation, wind speed and direction were available for analysis.

From the total of filters, 10 were excluded from the analysis due to technical issues during sampling. Therefore, we analyzed 28 filters collected during a 24-hour period and 32 filters collected during a 48-hour period. The 60 samples were tested for Cyn d 1 using the ELISA method. None of the samples showed any detectable levels.

To this day, the ELISA method used for Cyn $d 1$ in air samples has been an unprecedented technique. To ensure that the material used in the ELISA was working and that the elution method employed were reliable for extracting Cyn d 1, we carried out other assays. We tested the pure allergenic extracts (Immunotech ${ }^{\circledR}$ ) of Cynodon dactylon and Paspalum notatum as positive and negative controls, respectively. Cyn d 1 levels of $50 \mathrm{ng} / \mathrm{mL}$ were found in the Cynodon dactylon extract, and $2.28 \mathrm{ng} / \mathrm{mL}$ in the Paspalum notatum extract. In order to clarify whether the elution method was effective for Cyn d 1, the diluted Cynodon dactylon extract $(1: 1,000)$ was applied to the blank filter, and after drying, it was used the elution protocols. Cyn d 1 was detectable in concentrations ranging from 1.3 to $3.2 \mathrm{ng} / \mathrm{mL}$, which proves the reliability of the method.

The lack of Cyn d 1 allergen in any of the sample must be considered. The use of only Cynodon dactylon allergen for analysis introduces a bias in the study since Cyn d 4, which is also considered a major allergen of this species, was not analyzed. Another aspect to discuss is the number of sampled days. There were 60 samples collected over a one-year period from a single site in the city. These samples could not be representative of an entire year and the allergen could have been detected in other days. However, this hypothesis is unlikely if we consider that the meteorological data found during the 60 days of sample collection were equivalent to those found throughout the year ( $p>0.05$, CI 95\%, $t$ - student test). Thus, one site of air sample collection is enough to capture pollens of a region, since they can travel hundreds of kilometers, regardless of the distance of their source [14]. Given that studies have found an increasing sensitization to Cynodon dactylon in the Brazilian population [12,15], the allergic sensitization to Cynodon dactylon found in the region of Maringá is incoherent with the undetected Cyn d 1 levels. We suggested two hypotheses to justify these results. The first one is that sensitization could occur even in the presence of low concentrations of this allergen. In aeropalinological studies conducted in Caxias do Sul, another southern Brazilian city, the presence of pollen grains was detected throughout the year [16]. Recently, in Curitiba, grass pollen dispersion was observed from August to April [9]. This pattern of pollen dispersion is most evident in subtropical and tropical areas, given that there are no well-defined seasons between the Tropic of Capricorn and equator [17].

The second hypothesis for this result was that the presence of Cyn d 1 serum-specific IgE antibodies may occur at low levels in individuals with high positivity to $\mathrm{Phl}$ p 1 due to cross-reactivity to group 1, without representing proper sensitization to Cynodon dactylon [18]. In addition, the allergenic component used in this test is a natural allergen (nCyn d 1) glycosylated in the amino-terminal portion, which may imply a specific IgE response to nCyn $\mathrm{d} 1 \mathrm{in}$ populations not exposed to Cynodon dactylon. The glycosylation present in nCyn $\mathrm{d} 1$ is responsible for the production of IgE to crossreactive carbohydrates determinants (CCD), epitopes in several plant species and insect venoms that determine a sensitization to clinically irrelevant antigens [19].

Some limitations to the study are that the samples came from a single location in the city and reflect only that point. The sampled days were chosen based on convenience. Excessively rainy days were automatically ruled out since the device could not be exposed to heavy rain. The 48 -hour samples in particular may have shown protein losses due to the long sampling period in higher-than-average temperatures. The absence of detectable Cyn $\mathrm{d} 1$ in the air should be viewed with caution, considering that the allergenic grass is present in the region and people are sensitized to this type of grass.

Despite the undetectable levels of Cyn $d 1$ in the present study, this was the first attempt at using the ELISA method to identify this Cynodon dactylon allergen in the environment. Environmental studies of aeroallergens are essential to the practice of allergists because it enables us to understand the patient's environmental exposure, identify risks, introduce preventive measures, and draw up personalized treatment. We recommend that this study be reproduced with different components to highlight the diversity and degree of allergenic exposure of individuals in the environment that they live.

\section{Acknowledgement}

The authors would like to thank the ALK-Abelló Laboratory providing all for the ELISA material for Cyn d 1 measurements. 
The authors would like to thank Prof Ricardo Godoi, from Environmental Engineering at the Federal University of Paraná, who provided the impactor for the collection of samples. We also thank Prof Ernesto Taketomi and his team from Laboratory of Allergy and Clinical Immunology at the Federal University of Uberlândia who contributed to the analysis of the filter material.

\section{Author contributions}

CCTS and JSM contributed with data collection, interpretation and analysis of data, as well writing; NARF contributed with analysis of data, revision and content of this manuscript. EAT and RHMG contributed with critical revision and content of this manuscript. All authors have read and agreed to the published version of the manuscript.

\section{References}

1. Buters JTM. Pollen allergens and geographical factors. In: Akdis C Agache I, editors. Global atlas of allergy- EAACl. Zurich, 2014, Chapter 31: $36-38$.

2. Baldelli A, Jeronimo M, Loosley B, Owen G, Welch I, et al. Particle matter, volatile organic compounds, and occupational allergens: correlation and sources in laboratory animal facilities. SN Applied Sci. 2020; 2: 1-14.

3. Zahradnik E, Sander I, Bruckmaier L, Flagge A, Fleischer C, et al Development of a sandwich ELISA to measure exposure to occupationa cow hair allergens. Int Arch Allergy Immunol. 2011; 155: 225-233. PubMed: https://pubmed.ncbi.nlm.nih.gov/21282961/

4. Vieira FA, Ferreira EN, Cruz AA. Grass allergy may increase the risk of tree pollinosis. A warning to urban planners. J Allergy Clin Immunol. 1998; 102: 700-701.

PubMed: https://pubmed.ncbi.nlm.nih.gov/9802385/

5. Rosário NA. Pollinosis in Brazil: changing concepts. J Allergy Clin Immunol. 1990; 85: 819-820.

PubMed: https://pubmed.ncbi.nlm.nih.gov/2324422/

6. Rosário Filho NA. Contagem de polens aéreos na cidade de Curitiba. Rev Bras Alerg Imunopatol. 1983; 6: 12-15.

7. Vieira FAM. Gramíneas tropicais alergênicas: Cynodon dactylon e Paspalum notatum - uma visão para o trópico brasileiro. Rev Bras Alerg Imunopatol. 2012: 35: 40-41.

8. D'Amato G, Chong-Neto HJ, Monge Ortega OP, Vitale C, Ansotegui I, et al. The effects of climate change on respiratory allergy and asthma induced by pollen and mold allergens. Allergy. 2020; 75: 2219-2228. PubMed: https://pubmed.ncbi.nlm.nih.gov/32589303/

9. Camargo J, Brill S, Thom de Souza C, Sebben B, Pauliquevis T, et al. The advance in Poaceae pollen seasonality pattern may impact allergy treatment practice. J Allergy Clin Immunol. 2021; 147: AB85.

10. Bernardes CT, Moreira PF, Sopelete MC, Viera FA, Sung SS, et al. IgE cross-reactivity between Lolium multiflorum and commercial grass pollen allergen extracts in Brazilian patients with polinosis. Braz J Med Biol Res. 2010; 43: 166-175.

PubMed: https://pubmed.ncbi.nlm.nih.gov/20098843/

11. García-Mozo H. Poaceae pollen as the leading aeroallergen worldwide: A review. Allergy. 2017; 72: 1849-1858.

PubMed: https://pubmed.ncbi.nlm.nih.gov/28543717/

12. Araujo, LML, Rosário NA, Mari A. Molecular-based diagnosis of respiratory allergic diseases in children from Curitiba, a city in Southern Brazil. Allergol Immunopathol (Madr). 2016; 44: 18-22. PubMed: https://pubmed.ncbi.nlm.nih.gov/25982581/

13. Duffort O, Calabozo B, González R, Carpizo JA, Barber D, Polo F. Monoclonal antibody-based ELISA to quantify the major allergen of Cynodon dactylon (Bermuda grass) pollen, Cyn d 1. Int Arch Allergy Immunol. 2004; 135: 277-283.

PubMed: https://pubmed.ncbi.nlm.nih.gov/15564768/

14. Rousseau DD, Schevin P, Duzer D, Cambon G, Ferrier J, et al. New evidence of long distance pollen transport to southern Greenland in late spring. Rev Palaeobotany Palynol. 2006; 141: 277-286.

15. Moreira PFS, Gangl K, Vieira FAM, Ynque LH, Linhart B, et al. Allergen Microarray Indicates Pooideae sensitization in Brazilian grass pollen allergic patients. PLoS ONE. 2015; 10: e0128402. PubMed: https://pubmed.ncbi.nlm.nih.gov/26067084/

16. Vergamini SMN, Zoppas BCDA, Valencia-Barrera RM, FernandezGonzalez D. Dinâmica aeropalinológica de Gramineae na cidade de Caxias do Sul, RS. Rev. Bras. Alerg Imunopatol. 2006; 29: 14-17.

17. Davies JM, Matricardi PM, Schmid J. Grass Pollen Allergy. In: In EAACl Molecular Allergology user's Guide - EAACI, Zurich, 2016: 85-94.

18. Kailaivasan TH, Timbrell VL, Solley G, Smith WB, McLean-Tooke A et al. Biogeographical variation in specific IgE recognition of temperate and subtropical grass pollen allergens in allergic rhinitis patients. Clin Translational Immunol. 2020; 9: e1103.

PubMed: https://www.ncbi.nlm.nih.gov/pmc/articles/PMC6997006/

19. Cabauatan CR, Lupinek C, Scheiblhofer S, Weiss R, Focke-TejkI M, etal. Allergen microarray detects high prevalence of asymptomatic $\mathrm{IgE}$ sensitizations to tropical pollen-derived carbohydrates. J Allergy Clin Immunol. 2014; 133: 910-914.

PubMed: https://www.ncbi.nlm.nih.gov/pmc/articles/PMC6597356/ 